\title{
Relation between general practices' outpatient referral rates and rates of elective admission to hospital
}

\author{
Angela Coulter, Valerie Seagroatt, Klim McPherson
}

\begin{abstract}
Objective-To examine the variation in rates of admission to hospital among general practices, to determine the relation between referral rates and admission rates, and to assess the extent to which variations in outpatient referral rates might account for the different patterns of admission.

Design-A comparison of outpatient referral rates standardised for age and sex and rates of elective admission to hospital for six specialties individually and for all specialties combined.

Setting-19 General practices in three districts in Oxford Regional Health Authority with a combined practice population of $\mathbf{1 8 8 6 1 0}$.

Main outcome measures-Estimated proportion of outpatient referrals resulting in admission to hospital, extent of variation in referral rates and admission rates among practices, and association between admissions and outpatient referrals.

Results-Patients referred to surgical specialties were more likely than those referred to medical specialties to be admitted after an outpatient referral. Overall, the estimated proportion of patients admitted after an outpatient referral was $42 \%$. There were significant differences among the practices in referral rates and admission rates for most of the major specialties. The extent of systematic variance in admission rates (0.048) was similar to that in referral rates $(0.037)$. Referral and admission rates were significantly associated for general surgery; ear, nose, and throat surgery; trauma and orthopaedics; and all specialties combined. For most specialties the practices with higher referral rates also had higher admission rates, casting doubt on the view that these practices were referring more patients unnecessarily.
\end{abstract}

Conclusion-Rates of elective admission to hospital vary systematically among general practices. Variations in outpatient referral rates are an important determinant of variations in admission rates.

Epidemiology, University of Oxford, Oxford Regional Health Authority, Oxford

OX3 7LF

Angela Coulter, MSC, primary care research officer

Valerie Seagroatt, MSC, statistical research officer

Department of Public Health and Primary Care, University of Oxford, Radcliffe Infirmary, Oxford OX2 6HE

Klim McPherson, PHD, university lecturer in medical statistics

Correspondence to: $\mathrm{Ms}$ Coulter.

Br Med f 1990;301:273-6 to be the gatekeepers to secondary care, isions about when a referral is necessary and choosing the appropriate specialist. As the patient's agent they are therefore responsible for shaping the demand for hospital services. In the British system almost every non-emergency admission to hospital is the result of at least two clinical decisions: the general practitioner's decision to refer and the specialist's decision to admit.

The recent white paper Working for Patients ${ }^{1}$ expressed concern about wide variations in the rates of use of health care. General practitioners' referral rates to outpatient departments have been found to vary among practices by at least threefold or fourfold. ${ }^{2}$ Wide variations in the rates of admission to hospital for many common conditions also exist among geographical areas within the country. ${ }^{4}$ Mostly, these variations do not seem to be related to underlying patterns of disease in the population. Explanations have focused on differences in the availability of resources, patients' expectations, and styles of clinical practice.

In an attempt to promote a more rational use of resources the government has introduced measures designed to encourage general practitioners to reassess their referral patterns. From April 1991 doctors will have to include their rate of referral to each hospital specialty in their annual report to the family health services authority ${ }^{5}$ and will have to be prepared to discuss their referral rates with the authority's medical advisers. Presumably this measure is designed to focus attention on the outliers, particularly the practices with high referral rates, on the assumption that some practices are sending patients to hospital unnecessarily.

Expecting that a patient will be admitted to hospital is only one reason for referral to an outpatient department. Other reasons include the need for diagnosis and investigation, outpatient treatments or procedures, and advice or reassurance. ${ }^{6}$ Little is known about the relation between outpatient referral rates and admission rates, although an individual practice's referral pattern would seem likely to influence the rate at which their patients are admitted to hospital. In theory admission rates should vary less than referral rates because specialists would be expected to make more uniform decisions than general practitioners owing to their greater experience of the particular conditions referred to their specialty. If the practices with high referral rates are sending more patients to specialist clinics unnecessarily the proportion of patients admitted to hospital from these practices would be expected to be lower.

We analysed data from the Oxford record linkage study and from a study of practice referral rates to determine how the pattern of variation in referral rates among general practices compared with that in hospital admission rates and whether there was any association between practice referral rates and admission rates. In addition, we examined whether any evidence suggested that practices with high referral rates were referring some patients unnecessarily.

\section{Methods}

\section{OUTPATIENT REFERRAL RATES}

Data on outpatient referral rates came from a collaborative study of referrals by 127 general practitioners conducted in 1983-4 in Oxford Regional Health Authority. The methods have previously been described in detail. ${ }^{367}$ Briefly, general practitioners recorded data on all patients referred to outpatient 
clinics in all hospital specialties (private and NHS) in all districts for two 11 week periods in 1983 and 1984 . As the Hospital Activity Analysis returns excluded admissions to private hospitals and hospitals outside the boundaries of the regional health authority we included only the referrals to NHS hospitals within the Oxford region in the analysis.

\section{ADMISSION RATES}

Routine Hospital Activity Analysis returns in the Oxford region include a code indicating the general practice with which inpatients are registered. The Oxford record linkage study produced a patient linked data set based on these inpatient records. ${ }^{8}$ From this we abstracted data on patients electively admitted to hospital from each practice during 1983-5 (including day cases, all patients who had been on waiting lists, and all who had had booked admissions and booked readmissions but excluding those who had had emergency admissions). If a patient had been admitted to one specialty more than once in a year only the first elective admission in each year was included. We included admissions over the whole of the three years 1983-5 to provide a stable estimate of admission rates. We chose this period so that all admissions that might have arisen as a result of referrals made during 1983-4 would be included.

\section{SELECTION OF PRACTICES}

We have used data from 19 of the 33 practices in the original referral study. We included only those practices that were located in Oxfordshire, Milton Keynes, or Northampton District Health Authorities and that were able to supply detailed age-sex breakdowns of their practice populations for the study period. In total 188610 patients were registered with these 19 practices: 58646 in seven Oxfordshire practices, 68575 in seven Milton Keynes practices, and 61389 in five Northampton practices.

TABLE I-Rates of outpatient referral and elective admission per 1000 population per year for patients registered with 19 practices

\begin{tabular}{|c|c|c|c|c|c|}
\hline \multirow[b]{2}{*}{ Specialty } & \multicolumn{2}{|c|}{ Referrals } & \multicolumn{2}{|c|}{ Admissions } & \multirow[b]{2}{*}{$\begin{array}{l}\text { Estimated } \% \text { of referred } \\
\text { patients admitted }\end{array}$} \\
\hline & $\begin{array}{c}\text { Total No } \\
\text { (over } 22 \text { weeks) }\end{array}$ & Annual rate & $\begin{array}{c}\text { Total No } \\
\text { (over } 3 \text { years) }\end{array}$ & Annual rate & \\
\hline General surgery & 1330 & $17 \cdot 6$ & 6171 & $11 \cdot 0$ & 63 \\
\hline General medicine & 797 & $10 \cdot 5$ & 1483 & $2 \cdot 6$ & 25 \\
\hline Gynaecology & 830 & $11 \cdot 0$ & 4253 & $7 \cdot 5$ & 68 \\
\hline Ear, nose, and throat & 804 & $10 \cdot 6$ & 2994 & $5 \cdot 3$ & 50 \\
\hline Trauma and orthopaedics & 731 & $9 \cdot 7$ & 2272 & $4 \cdot 0$ & 41 \\
\hline Ophthalmology & 457 & $6 \cdot 0$ & 773 & $1 \cdot 4$ & 23 \\
\hline $\begin{array}{l}\text { All specialties including } \\
\text { those above }\end{array}$ & 6193 & $81 \cdot 8$ & 19248 & $34 \cdot 2$ & 42 \\
\hline
\end{tabular}

TABLE II - Sources of variation among practices in standardised referral rates and standardised admission rates

\begin{tabular}{|c|c|c|c|c|c|c|}
\hline Specialty & $\begin{array}{c}\text { Total } \\
\text { variance }\end{array}$ & $\begin{array}{c}\text { Coefficient } \\
\text { of variation } \\
(\%)\end{array}$ & $\begin{array}{l}\text { Adjusted } \\
\text { variance }^{\star}\end{array}$ & $\begin{array}{c}\text { Coefficient } \\
\text { of variation } \\
(\%)\end{array}$ & $\begin{array}{c}\text { Systematic } \\
\text { variance }\end{array}$ & $\begin{array}{c}\text { Coefficient } \\
\text { of variation } \\
(\%)\end{array}$ \\
\hline \multicolumn{7}{|l|}{ General surgery: } \\
\hline Referral rates & $0 \cdot 068$ & 29 & $0 \cdot 075$ & 31 & $0 \cdot 055$ & 27 \\
\hline Admission rates & $0 \cdot 052$ & 26 & $0 \cdot 051$ & 25 & 0.047 & 24 \\
\hline \multicolumn{7}{|l|}{ General Medicine: } \\
\hline Referral rates & $0 \cdot 188$ & 54 & $0 \cdot 080$ & 33 & 0.047 & 24 \\
\hline Admission rates & $0 \cdot 195$ & 56 & 0.063 & 28 & 0.044 & 23 \\
\hline \multicolumn{7}{|l|}{ Gynaecology: } \\
\hline Referral rates & $0 \cdot 124$ & 42 & $0 \cdot 116$ & 41 & 0.086 & 34 \\
\hline Admission rates & 0.055 & 26 & 0.055 & 26 & $0 \cdot 049$ & 25 \\
\hline \multicolumn{7}{|c|}{ Ear, nose, and throat: } \\
\hline Referral rates & $0 \cdot 123$ & 42 & $0 \cdot 103$ & 38 & 0.071 & 31 \\
\hline Admission rates & $0 \cdot 116$ & 41 & $0 \cdot 127$ & 43 & $0 \cdot 118$ & 41 \\
\hline \multicolumn{7}{|c|}{ Trauma and orthopaedics: } \\
\hline Referral rates & $0 \cdot 157$ & 49 & $0 \cdot 164$ & 49 & $0 \cdot 129$ & 43 \\
\hline Admission rates & 0.067 & 30 & 0.073 & 31 & 0.062 & 28 \\
\hline \multicolumn{7}{|l|}{ Ophthalmology: } \\
\hline Referral rates & 0.052 & 26 & 0.057 & 27 & 0.0 & 0 \\
\hline Admission rates & $0 \cdot 108$ & 39 & 0.065 & 29 & 0.030 & 19 \\
\hline \multicolumn{7}{|l|}{ All specialties: } \\
\hline Referral rates & $0 \cdot 048$ & 24 & $0 \cdot 042$ & 23 & 0.037 & 21 \\
\hline Admission rates & $0 \cdot 050$ & 25 & $0 \cdot 050$ & 25 & $0 \cdot 048$ & 25 \\
\hline
\end{tabular}

^Adjusted for difference among districts.
Of the 14 practices excluded, five were unable to supply age-sex breakdowns, four had dropped out during the second phase of the referral study, one straddled the regional boundary and referred most patients to another regional health authority, one increased its list size by a third between the two phases of the referral study, and three were in other districts (two in West Berkshire; one in East Berkshire). In addition: one practice had split into two during the referral study but was counted as one as it was not possible to separate the data on admissions.

\section{STATISTICAL METHODS}

Referral and admission rates were standardised for age and sex by the indirect method. The standard population was the total population of the 19 practices divided into 10 year age bands by sex. Rates of referral and admission were expressed as annual rates. Variation among practices was assessed by a method adapted from the proportional hazards model, ${ }^{9}$ in which the random component due to Poisson variability is subtracted from the total variance of the standardised rates to give an estimate of the systematic component of variation. Differences between systematic components of variance were tested by calculating their ratios and comparing them with standard tables of the $F$ distribution.

Rates could also vary among districts. Analysis of variance was used to assess the significance of any differences among the districts, and the variation among districts was then subtracted from the total variance. The adjusted variance was divided into the random and systematic components as described above. We also expressed these variances, before and after the subtraction of the random component, in a form similar to the coefficient of variation-that is, the square root of the variance expressed as a percentage of the mean rate.

The association between the standardised rates of referral and admission for individual specialties and all specialties together was examined by regression analysis. The significance of a linear relation was assessed after adjustment for possible differences among the districts. Separate regression lines were fitted for each district, with each having the same slope. (Lines with different slopes were also fitted, but in no case did these slopes differ significantly $(p>0 \cdot 1)$.) The percentage of the variance in the admission rates explained by the linear association with referral rates, $\left(\mathrm{R}^{2}\right)$ was calculated, where $\mathrm{R}$ was the pooled correlation coefficient.

Admission and referral rates were further examined to see whether admission rates were linearly related to referral rates over their complete range or whether the relation changed for high or low referral rates. This was assessed by testing the significance of including a quadratic term into the regression model.

\section{Results}

Table I gives the annual outpatient referral rates and elective admission rates by specialty and for all specialties along with the estimated percentages of referrals resulting in hospital admissions. Most of the patients referred to general surgery $(63 \%)$ and gynaecology $(68 \%) ; 50 \%$ of those referred to ear, nose, and throat surgery; and $41 \%$ of those referred to trauma and orthopaedics were admitted for hospital treatment, whereas only $25 \%$ of those referred to general medicine and $23 \%$ to ophthalmology were admitted.

In general medicine both the referral rates and the admission rates differed significantly among the districts ( $F=8$ (referrals), $F=21$ (admissions); $\mathrm{df}=2$, 16). This variation accounted for $49 \%$ and $73 \%$ respectively of the total variance in the standardised rates. 
Significant differences among districts were also found in the admission rates for ophthalmology (accounting for $42 \%$ of the total variance). Significant differences among districts were not found for any other specialty or for all specialties together.

Table II shows the total variability among practices before and after adjustment for differences among the districts and the systematic component of variance after subtracting the random Poisson component. There were significant differences among the practices in referral rates and admission rates for each of the specialties, with the exception of referral rates to ophthalmology. Comparing the systematic variance
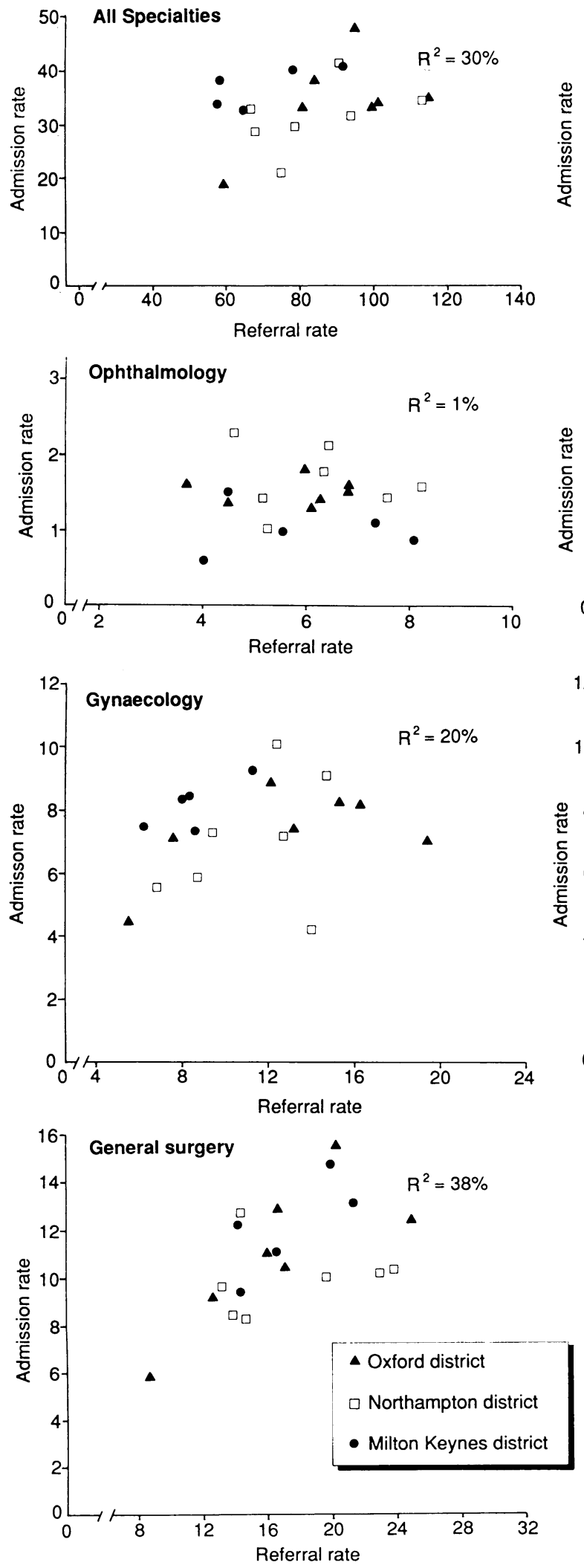

between referral rates and admission rates showed two specialties (gynaecology; trauma and orthopaedics) in which the referral rate varied more than the admission rate and two (ear, nose, and throat surgery; ophthalmology) in which referrals showed less variation. In the two remaining specialties (general surgery; general medicine) and in all specialties together the variations between practices' referral and admission rates were similar.

The figure shows the relation between practices' referral and admission rates. The association between referral rates and admission rates was found to be significant $(p<0.05)$ for general surgery; ear, nose and
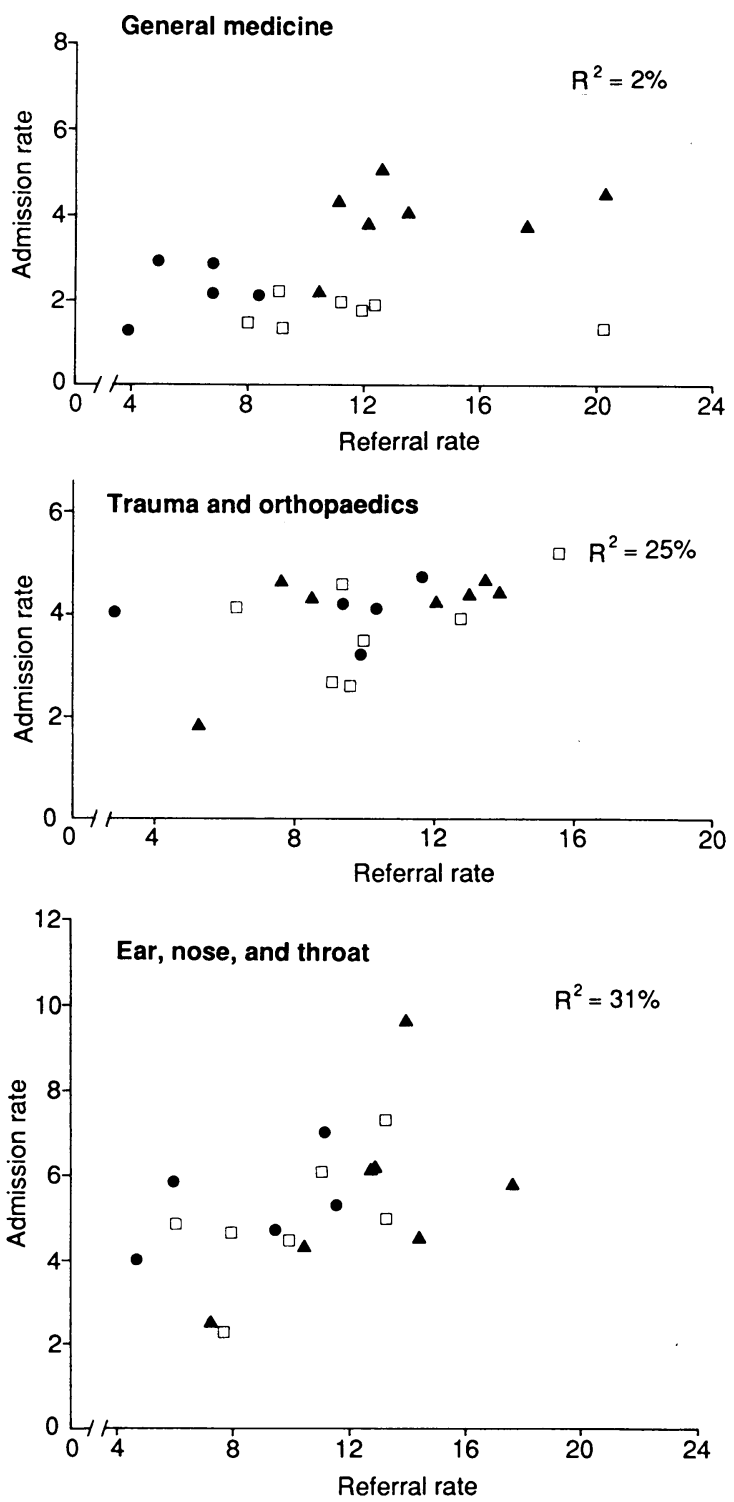

Association between outpatient referral rates and elective admission rates for 19 general practices. Rates expressed per 1000 population per year 
throat surgery; trauma and orthopaedics; and all specialties together but not for general medicine and ophthalmology. Gynaecology showed some evidence of an association $(0.05<\mathrm{p}<0 \cdot 1)$, but this did not reach conventional levels of significance.

The presence of any levelling off effect was assessed by including a quadratic term in the regression model. Levelling off was significant only for general surgery, explaining a further $20 \%$ of the variance $(F=6 \cdot 4, \mathrm{df}=$ $1,14 ; \mathrm{p}<0.01)$. For gynaecology the quadratic term explained $18 \%$ of the variance, but again the term was not significant $(F=4 \cdot 0 ; \mathrm{df}=1,14 ; 0 \cdot 05<\mathrm{p}<0 \cdot 1)$. For the other specialties and all specialties together the quadratic term explained less than $10 \%$ of the variance.

\section{Discussion}

Not all admissions to hospital are the result of an outpatient referral from a general practitioner. Several other routes exist for admission, including emergency admission through an accident and emergency department and referral from another hospital department. Nevertheless, referral to an outpatient department is the first step to admission for most elective surgery, and our data show that the likelihood of admission after an outpatient referral is much higher in the surgical specialties than in other specialties. The association between outpatient referral rates and nonemergency admissions in these specialties supports the view that referral patterns in primary care are an important influence on rates of elective surgery.

Variations in referral rates among general practices have received more attention in Britain than variations in their rates of admission of patients. Our study, however, suggests that admission rates are no less variable, and in the cases of ear, nose, and throat surgery and ophthalmology they are more so. Variations among general practices in the same district seem unlikely to be the result of different patterns of disease or differences in the availability of resources. ${ }^{10}$ The most likely cause of the systematic variation observed here is differences in styles of clinical practice.

A consensus is developing that differences in styles of practice are due to clinical uncertainty in the face of limited evidence about the effectiveness of treatments. " There is greater disagreement about appropriate treatment for certain conditions than for others, and these disagreements cause large variations in rates of admission among adjacent small areas in several countries. ${ }^{12}$ Rates of admission to medical specialties have been found to be more variable than those to surgical ones in North American studies, ${ }^{13 / 4}$ and this was also found in our study.

Our findings suggest that variations in referral patterns are an important determinant of variations in hospital admission rates in Britain. Variations in referral rates cannot be explained by any easily measured characteristics of doctors or patients, ${ }^{15}$ and clinical uncertainty about the most appropriate investigation or treatment for many common conditions is probably the underlying cause of the differing patterns. We found three patterns of association between referral rates and admission rates depending on the specialty: firstly, an association between low admission and referral rates but less of an association between higher rates (general surgery and possibly gynaecology); secondly, an association between high admission and referral rates (ear, nose, and throat surgery and trauma and orthopaedics); and, thirdly, little or no association between the rates (general medicine and ophthalmology).

The first pattern suggests a levelling off in admissions from the practices with high referral rates. The average referral rate may be optimal for these specialties if the specialists' judgments are correct. In that case practices with both high and low referral rates should reconsider their current practices. The absence of levelling off in the second pattern suggests two competing hypotheses: either the specialists have a threshold of severity for admission and even the patients from the practices with high referral rates cross that threshold or the specialists admit a fixed proportion of referred patients, as has been reported for tonsillectomy, ${ }^{16}$ and there is no optimum threshold for admission. If either hypothesis is true it may be wrong to assume that practices with high referral rates are sending too many patients unnecessarily to outpatient departments. Practices with average or low referral rates may be depriving their patients of beneficial hospital treatment.

Admission rates in this study were as variable as referral rates, underlining the uncertainty that characterises clinical decision making in hospital specialities as well as in general practice. It may therefore be misleading to look to specialist opinion for a standard against which to judge the appropriateness of referrals.

In conclusion, we agree that information about rates of referral or admission cannot be used to judge quality meaningfully. ${ }^{178}$ More evidence is needed on the outcomes of referral and the effectiveness of treatment to enable sound judgments about appropriateness of referral rates to be made.

We thank the general practitioners and their staff for their help; Ahilya Noone and Michael Goldacre for the data on referrals; and Myfanwy Griffith for help with computing. The unit of clinical epidemiology is part of the department of public health and primary care, University of Oxford, and is funded by the Department of Health and Oxford Regional Health Authority.

1 Secretaries of State for Health, Wales, Northern Ireland, and Scotland. Working for patients. London: HMSO, 1989. (Cmnd 555 .)

2 Crombie DL, Fleming DM. General practitioner referrals to hospital: the financial implications of variability. Health Trends 1988;20:53-6.

3 Noone A, Goldacre M, Coulter A, Seagroatt V. Do referral rates vary widely between practices and does supply of services affect demand? $7 R$ Coll Gen Pract 1989:39:404-7.

+ Sanders D, Coulter A, McPherson K. Variations in hospital admission rates: a reviezi of the literature. London: King Edward's Hospital Fund for London, 1989.

5 Department of health. Terms of service for doctors in general practice. London DoH, 1989.

6 Coulter A, Noone A, Goldacre M. General practitioners' referrals to specialis outpatient clinics. I. W'hy general practitioners refer patients to specialis outpatient clinics. Br.Med F 1989;299:304-6.

7 Coulter A, Noone A, Goldacre M. General practitioners' referrals to specialis outpatient clinics. II. Locations of specialist outpatient clinics to which general practitioners refer patients. Br Med f 1989;299:306-8.

8 Goldacre MJ, Simmons H, Henderson J, Gill LE. Trends in episode based and person based rates of admission to hospital in the Oxford record linkage and person based rates of admission to
study area. $B r$ Med $\mathcal{f}$ 1988:296:583-4.

9 McPherson K, Wennberg J, Hovind O, Clifford P. Small-area variation in the use of common surgical procedures: an international comparison of New England, England and Norway. N Engl F Med 1982;307:1310-4

10 McPherson K. Variations in hospitalisation rates: why and how to study them. In: Ham C, ed. Health care variations: assessing the evidence. London: King' Fund Institute, 1988.

11 Eddy DM. Variations in physician practice: the role of uncertainty. Healt Affairs 1984;3:74-89.

12 McPherson K, Strong PM, Epstein A, Jones L. Regional variations in the use of common surgical procedures: within and between England and Wales, Canada and the United States of America. Soc Sci Med 1981;15A:273-88.

13 Wennberg JE, McPherson K. Caper P. Will payment based on diagnosisrelated groups control hospital costs? N Engl f Med 1984;311:295-300.

14 Roos NP, Wennberg JE, McPherson K. Using diagnosis-related groups for studying variations in hospital admissions. Health Care Financing 1988; 9:53-62.

$15 \mathrm{~W}^{\prime}$ ilkin D, Smith AG. Explaining variation in general practitioners' referrals to hospital. Fam Pract 1987;4:160-9.

16 Bakwin H. Pseudodoxia pediatrica. N Engl f. Med 1945;232:691-7.

16 Bakwin H. Pseudodoxia pediatrica. N Engl f Med $1945 ; 232: 691-7$.
17 Wilkin D, Metcalfe D, Marinker M. The meaning of information on (GP Wilkin D, Metcalfe D, Marinker M. The meaning of in
referral rates to hospitals. Community. Med 1989;11:65-70.

18 Knottnerus J, Joosten J, Daams J. Comparing the quality of referrals of general practitioners with high and average referral rates: an independen panel review. British fournal of (ieneral Practice 1990;40: 178-81.

Accepted 4 June 1990 